This is a final version of an accepted manuscript published in Annals of Leisure Research by Taylor and Francis available here with citation details Leisure and health - critical commentary (tandfonline.com)

\title{
Leisure and Health - Critical Commentary
}

\section{Mansfield, L (2021)}

\section{Introduction}

As Leisure Studies scholars around the world adjust to the COVID-19 pandemic, the significance of critical leisure studies perspectives for understanding public health is discernible. Leisure studies might best be described as a broad and diverse assemblage of researchers engaging with leisure from a range of disciplinary and ontological perspectives, bringing multiple and contested theoretical and methodological trajectories to intellectual scholarship on leisure (Silk, Caudwell and Gibson, 2017). As such, the field provides a formidable opportunity in this current moment to make sense of leisure and health in terms of the interconnections between local, national and global movements of people, goods and services, political and economic agendas, and individual and community experiences of difference, diversity and social inequalities. However, grave as it is, the current COVID-19 pandemic is one of many public health crises that humanity has faced throughout history with potential implications for the health-related features of our leisure lives. In its most rigorous theoretical and methodological approaches, leisure studies proffer historically situated critical analysis, recognising that the interplay between leisure, culture and public health develop over time as well as in the context of present-centred political and economic forces. The multidisciplinary and cross-sector framing of the critical, ethical inquiry that is at the heart of leisure studies provides a scholarly medium through which to respond to the complexities of everyday health challenges and extraordinary public health crises that populations may be facing in the present. In this analytical mode, the field of leisure studies also offers an opportunity for reflexive analysis of past and potential future directions about the intersections of leisure and health and the wider sociocultural, political and economic contexts in which they take place.

This critical commentary presents a broad and necessarily selective overview of conceptual, theoretical and methodological trajectories in leisure and health. It provides much more detail about conceptual and theoretical approaches, but also alludes to methodological approaches in the debates. It does so with some attention to global perspectives although many of the specific examples have a UK focus. The literature included here reflects critical scholarship about the meanings and practices of health in the leisure sphere. Different theoretical and conceptual accounts of health provide evidence of competing, complex and often discrete bodies of thought about leisure and health relations in terms of control and compliance and autonomy and opposition. These directions of academic thought have contested intellectual, social, political and economic canons and consequences. The multiple and contested theories of health and the diverse array of approaches and techniques for measuring and evaluation are significant for critical leisure studies because they give rise to markedly different interpretations of the meanings of health, separate strategies for addressing acclaimed problems of health and diverse thinking about the relationships between leisure and health. The commentary does not include a synthesis of evidence on leisure 
and wellbeing since wellbeing is a different albeit interconnected concept with an extensive theoretical and methodological corpus of work which is beyond the scope of this short paper and explained elsewhere (Mansfield et al., 2020). I illustrate where leisure studies work has made a significant contribution to understanding health and identify areas for advancing scholarship on leisure and health relations.

\section{Conceptual, theoretical and methodological trajectories in leisure and health}

Leisure in all its culturally embedded manifestations includes a remarkable variety of opportunities for people to engage in activities that have a positive impact on their health. Leisure activities chosen by people to suit their identities, life circumstances and life stage have the potential to enhance peoples' health be that in physical, psychological and/or sociocultural ways. There is a wealth of evidence underpinned by ideologies of epidemiological, medical and economic rationality showing that leisure (typically physical activity, arts and music) is effective in addressing acclaimed population level health problems through a reduction of risk, prevention or treatment of poor mental and physical health (see for example reviews by Bailey, 2014; Daykin, 2019; Pedisic, 2019). Such work typically follows established methodological principles in public health emphasising either direct measurement of health outcomes by quantitative techniques or examination of determinants of health (operationalised as physical and mental conditions) using qualitative methods. Leisure activities are strongly associated with the creation and maintenance of good public health, the imperative of virtue, self-discipline and status (Lupton, 1995). However, the idea of a universal, direct and incontrovertible link between leisure and health is inaccurate and oversimplified. I have emphasised in other writing that health is a complex and contested concept (see for example, Mansfield and Malcolm, 2014; Mansfield, 2016; Mansfield 2017). Inequalities in health prevail on a local and global scale and in terms of the cumulative and intersecting influences of poverty, gender and sexuality, age, disability, ethnic grouping and social class (Bury and Gabe, 2004). Health and illness are not simply shaped by individual behaviours, but by complex structural inequality and a durable social gradient, revealing that globally those with worse health are those living in the poorest conditions and with the lowest socio-economic status (Marmot, 2005). As Kay (2017) points out, it is the distribution of wealth within nations that is as significant in understanding health inequality as the distribution of power between them. Whilst, worldwide, many people will expect to live relatively long lives with positive health experiences, others, in a variety of contexts (including the current COVID-19 pandemic), are faced with situations in which their health is weakened, in jeopardy, or a problem requiring conscious effort (Albrecht et al., 2000). Health, then, is culturally specific as well as individual and interpersonal in nature. Health is socially constructed via multiple and contested conceptual trajectories, and concomitant debates about how human health should be promoted and protected, whose health should be prioritised and by what means, and in which contexts health matters.

Histories of leisure and studies of contemporary leisure cultures provide exemplars of the complexity and nuances in the leisure/health nexus. One common feature of leisure and health relations over time is the notion of corporeal control. In this regard, scholars have explored in some detail questions surrounding the regulation and restraint of individual bodies and the government of populations with evidence of very gradual and punctuated shifts between external social control and 
intensifying internal or self-regulation (see for example Foucault, 1979; Elias, 2000). In these wider sociological terms, then, leisure is revealed as a mechanism for the application of the rules, practices and expectations of health in any given time and space. Rational recreation as it took place in England in the mid to late $19^{\text {th }}$ century, for example, sought to use leisure activities, typically distinctive from work, to cultivate respectability in the working classes through a parallel ideological reinforcement of health and morality (Hargreaves, 1992). Such developments arguably reflected the emerging politics and practice of the establishing health system, nurturing regimes of personal and public hygiene for protecting and improving public health (Armstrong, 1993). Through legislative and educational reforms and enthusiastic support from reformers in both middle and working classes, there was a systematic and sustained effort to replace popular forms of leisure associated with debauchery and unsanitary conditions (e.g. cock fighting, bear baiting, bird singing, street gambling and drinking in public houses) with health improving and virtuous practices taking place in new and clean environments such as museums, libraries, parks and exhibitions spaces (Bailey, 2014). The influence of such rational recreational endeavours for working-class men was matched by a "rational domesticity" that saw middle-class women teaching the standards and practices of homemaking to working-class women. A type of philanthropic leisure embedded the principles and practices of orderliness and hygiene to working-class women's lives although the paradox that bourgeois women were escaping the confines of their own domesticity only to teach such restrictions to working-class women were evident (Clark and Critcher, 1985, p.64). This kind of conspicuous leisure also marked the recreational practices of middle-class women whose choices of leisure reflected a classed and gendered notion of refinement and social standing. Physically bound by their corsetry, such women's participation in leisure practices including croquet and tennis, which signalled decorum and a "fashionable accomplishment", symbolic of health as wealth and status irrespective of the potential negative physical and/or mental consequences of such bodily control (Hargreaves, 1994, p. $53)$.

These examples illustrate overlapping class and gender systems of corporeal control and restraint in the $18^{\text {th }}$ and $19^{\text {th }}$ centuries (English) leisure and health relations. However, leisure practices also provided a potentially liberating arena for escape from regulatory norms albeit most often within the boundaries of established regulations and conventions. Adaptations to some (male) workingclass leisure represented less repressive forms of control and harnessed broader conceptions of health as enjoyment and pleasure, with music making as an example in the emergence of brass bands in northern regions of England and choral societies across countries in Europe and in Canada (Russell, 1997). The relative inclusion/exclusion of some groups over others in specific leisure activities is well-defined. Reflecting the prevailing pattern of racial and ethnic exclusion of the time, participation in leisure was overwhelming and often exclusively White meaning that opportunities for immigrant or indigenous populations to experience any potential health benefits of participation were limited or absent. Notwithstanding complex contextual and cultural factors at play, this reflects a broad pattern of exclusion, prohibition, restriction and withdrawal of resources in the histories of leisure and migrant and indigenous peoples around the world with negative consequences for the health of those populations (see for example Fox, 2006; Iwasaki and Bartlett, 2009; Tatz, 2020). A more sophisticated analysis of the complex exclusionary practices which organise and institutionalise racial and ethnic divides did not begin until the mid-20 th century (Floyd, 2007; Hylton, 2005; Aria and Kivel, 2009). Critiques of the organisation and consequences of other markers of marginalisation (e.g. age, sexuality and disability) and their intersections are also reflected in the leisure studies 
literature (Watson and Scraton, 2013), including the multiple ways in which leisure is a site for the accommodation, contestation and negotiation of health as will be illustrated.

Elsewhere, similar to other scholars, I have emphasised that the social and political imperative on lifestyle since the late $20^{\text {th }}$ century and the interpersonal character of health have served to preserve the marriage of health and morality (Howell and Ingham, 2001; Mansfield, 2017), but it is a point worth summarising again here. The prescription and promotion of health emphasises a surveillance approach to social and self-regulation (Armstrong, 1995; Nettleton, 2006). With advances in technological innovation in health and fitness the digital leisure sphere has ushered in a multiplicity of interactive, wearable technology for monitoring and tracking health throughout our social lives (Millington, 2017). Health promotion is resolutely targeted at all individuals in a population and frequently reinforced by an emphasis on health risk and disease prevention, rather than the existence of identifiable symptoms of illness (Lupton, 1995). There are opposing moral views about 'good/healthy' and 'bad/unhealthy' lifestyles and parallel judgements about those taking part in leisure activities deemed to be health improving or harmful to health (Shilling, 1993; Turner, 2000). Leisure activities involving physical activity have always been dominant in the prescription and promotion of public health. However, creative arts, music and wider cultural activities are also advocated as health-improving leisure activities (Stickley and Clift, 2017). Critical leisure scholars and those in other disciplinary fields examining leisure-type activities have explored experiences, promotion and representation of health from a range of conceptual and theoretical perspectives. Discussions have raised anew questions of health and corporeal control across stratified divisions in society. Arguably, scholarly work on gender (and to a lesser extent sexuality) and ageing has attracted the most extensive focus on leisure and health, but studies have also focused on disability and cultural difference and diversity. The following selected examples provide some illustration.

For feminist scholars, health-related disciplinary regimes of fitness in women's leisure reflect the establishment of cosmetic fitness and the commercial fitness industry serving to construct a predominantly outward aesthetic of health defined by narrow ideals of feminine beauty (Bartky, 1988, 1990; Bordo, 1990). The regulative regimes of commercialised fitness have been shown to conflate the fit body with health and promote fitness as the route to optimal heterosexual vigour, shape, size and happiness (Dworkin and Wachs, 2009). Dominant and destructive assumptions about fat bodies, for example, have been linked to stigmatising ideologies and processes that serve to discount and eliminate those categorised as overweight or obese from the very leisure activities that have the potential to enhance health (see for example Rich and Mansfield, 2019; Meadows and Bombak, 2019). Overall, work concerning the female body-beautiful and fitness cultures reflects the enduring motif in leisure and health relations about the intricate nature of corporeal social and selfcontrol over established notions of beauty and health (Markula, 1995; Maguire and Mansfield, 1998; Mansfield, 2010; Sassatelli, 2010; Smith-Maguire, 2007). Work in the leisure studies field also illustrates the contradictory nature of ideals of health and the possibilities for more self-directed articulations of individual meanings of health through physical activity (Wittels and Mansfield, 2019; Mansfield and Rich, 2010). Gender studies have also been central to developing scholarship on health in a digital age. Such work has revealed the complex and conflicting interplay between the governance of female bodies and pedagogical possibilities of resistance to established corporeal health norms (Rich, 2019). Issues of men and masculinity are not absent from examinations of health and leisure, and histories of leisure reveal sport and physical education as central to the 
establishment of a mens sano incorpore sana ethos (Hargreaves, 1986; Tomlinson, 2005). A focus on masculinity, leisure and broad issues of inequality and social justice more recently has left health as an under-researched issue and in addition men's health and leisure (typically football participation in the UK) has predominantly been explored within a biomedical model of public health in contemporary leisure literature (e.g Curran, et al., 2017; -Sufrategui et al,., 2017). There are notable exceptions, however, from scholars examining issues of men, sport, pain and suffering (see Atkinson, 2008; Pringle, 2003; Pringle et al., 2011), critical and significant sociological analysis of concussion injuries (Malcolm, 2019) insightful analysis in sports work, the emotions and mental health - applied to both men's and women's sports (see Roderick et al., 2017) and studies illustrating that there are contemporary representations and perceptions of fitness and idealised healthy male bodies also symbolic of the quest for health across the life course (Monaghan, 2014; Marshall and Katz, 2002; Risner and Watson, 2021; Watson and Rodley, 2015). In the context of studies on gender and sexuality, leisure researchers have implicitly explored imagined notions of health as part of a heteronormative framework of leisure provision and promotion (Caudwell and Brown, 2011). In doing so, scholarship has illustrated that the leisure practices of the LGBT community are commonly defined in terms of sexual risk and delinquency and therefore identified as a problem for public health (see for example Berdychevsky and Gibson, 2015; Jackson, 2008).

The literature relating to ageing and leisure has broadly established critical scholarship about the political, social and economic narrative which emphasises individual responsibility for lifelong health through all aspects of life including leisure (Katz, 2001; Pike, 2011). In the politics of active ageing, physical activity is upheld as the universal remedy for the acclaimed problems of ageing (i.e. illness, frailty, disability and loneliness) and a collective solution for ensuring lifelong health (Mansfield et al., 2019). However, scholars in the field contest the idea of a ubiquitous deficit model of ageing and physical activity (Tulle, 2007, 2008; Phoenix and Smith, 2011) as well as the capacity for physical activity to preserve lifelong health. Whilst leisure practices involving physical activity may not be available or suitable for the ageing population in its entirety, many older people take part in and enjoy them (Dionigi et al., 2013; Phoenix and Tulle, 2017). Engaging in leisure in later life, then, reflects complex interpersonal negotiations of ageing including contradictory and interacting encounters of resistance, redefinition and acceptance (Wearing, 1995; Wheaton, 2017). The possibilities of leisure for a more self-defined sense of health in older age is revealed in the literature on creative and participatory arts (from music and singing and photography to crafting, theatre, poetry and dance), which illustrates that participation in new or innovative forms of leisure provide for a capability model of health in older age (Clift and Camic, 2016; Liechty et al., 2012). In a broader life-course perspective, there is also some work in leisure studies which has focused on thinking beyond the biomedical dualism of health and illness, with a focus on a personal growth approach for understanding youth engagement and leisure. In this sense, leisure and nature practices have been shown to be a site for salutogenic and more self-defined health experiences for millennials (Young et al., 2018), and the complex and negotiated experiences of digital leisure have been highlighted as important in understanding the potential for reconstructing youth subjectivity and notions of mental health beyond biomedical conceptions (Fullagar et al., 2017a, 2017b)

The disability rights movement, most politically effectual in ensuring the implementation of antidiscrimination legislation in the UK and other liberal democracies around the world in the late $20^{\text {th }}$ century, is underpinned broadly by a social model of health. Eschewing the dominant medical model 
of health with its inherent assumptions about biological normality and the quest to overcome that deemed to be abnormal, the social model of health recognises the complex socio-cultural meanings and experiences of living with impairments and seeks to challenge and address disablist ideologies, policies and practices (Thomas, 2007). Further critical thinking about disability rights including a focus on health has most recently argued for a relational model emphasising the multiple and overlapping physical and social processes that characterise the experience of living with and beyond impairments (Smith and Perrier, 2014; Smith and Bundon, 2018). Such critical frameworks for thinking about disability have been employed in work on leisure where there is an intellectual focus on health and inclusive participation. Reflecting the wider work on the mental and physical health benefits of physical activity and arguably reflecting the dominance of a lifestyle agenda, studies have also shown that physically activity can reduce pain (Pinto et al., 2014), decrease the risk of cardiovascular disease and type 2 diabetes (Van der Ploeg et al., 2004), improve functionality (Tumasz, 2016) and reduce depression (Lee and Park, 2008) for some types of disability. Physical activity has once again been the prevailing leisure context for exploring the negative health consequences of disability in which scholars have identified barriers to participation including loss of corporeal function, pain, anxiety and depression, reduced self-confidence, social isolation, exclusion (ideological, material resource and environmental), lack of personal and professional support, including poor training of professional practitioners, and issues in the management of hopes and expectations (for an overview see Williams and Smith, 2017). Significant scholarly work on physical activity and disability has developed in studies of spinal cord injury, which have illustrated that barriers to participation reflect a nexus of personal, social, political and environmental issues (Williams et al., 2014). Prevailing challenges around personal knowledge about being active, professional support to engage in physical activity (or other leisure activities), coupled with powerful and enduring physical and emotional adjustments and the established rhetoric of exercise as medicine serve continued exclusionary structures and processes in leisure provision (Williams et al., $2014 ; 2018$ ). It remains the case that people living with disability are marginalised from leisure experiences that could benefit their health albeit within a conceptual framework of physical activity as medical intervention. However, scholars working in this area have argued for furthering an understanding of these experiences and addressing ways of developing high-quality provision through professional practice support, personal empowerment and investment in appropriate resources (Goodley and Moore, 2002; Samuels, 2015; Zijlstra and Vlaskamp, 2005).

The importance of understanding and reflecting cultural difference and diversity in public health promotion and practice has come to the fore as the limits of the biomedical model have been further scrutinised. There has been some progress in some areas of public health in recognising that perceptions, beliefs and values surrounding health differ across and within cultures, which has profound contextual implications for the way health is defined, designed, implemented and evaluated (Napier et al., 2014). In practice, stark inequalities exist across cultures in healthcare, health provision and lifestyle as an established social ideology, and inequities of health prevail. Identification of such inequalities without attention to wider social, political and economic contexts can reinforce taken for granted assumptions about which communities are a health 'problem', with groups being blamed for their failure to act on and resolve their health issues, and this is a common feature of public health prescription and promotion (see for example Smith, 2013). Leisure studies reflect a long-established theoretical and methodological approach which has significantly advanced knowledge about leisure and culture in terms of personal and social experiences of difference, 
diversity, and social inequality. Nonetheless, this identity and social justice framework has yet to fully and explicitly examine the intersections of leisure, health and cultural diversity. The potential for more critical analysis of cultural diversity, leisure and health is evidenced in work emphasising the significance of challenging Euro- and Western-centric models of health (Fox, 2006) and lifestyle (MacDonald et al., 2013), exploring the intersection of culture, narrative and the emotions in developing personal and community empowerment in leisure (Maxwell et al., 2019) and articulating the significance of spatial and cultural facets of everyday leisure (e.g. walking) in producing deeply meaningful socio-cultural experiences that move beyond essentialist discourses of public health (Ratna, 2017).

\section{Concluding comments and future directions in leisure and health}

Health provides a context for understanding leisure and social relationships in terms of an array of key issues, including the historical development of leisure, the growth of commercial leisure industries, social stratification, division and social interaction in leisure, representation of leisure in the media, the state and politics and leisure and work. As this critical commentary has shown, there is both established and emerging literature advancing scholarship about some of these issues and their complex socio-cultural, personal, political and policy relevance to understanding leisure and human health. However, leisure studies scholarship, introduced in this commentary as a critical and ethical form of inquiry, is strongly positioned to make a difference not only to leisure and health knowledge within the academy, but also to public health decision-making, and experiences of leisure-health practices around the world. To do so, scholars need to more explicitly and critically address the wider policy debates about the physical and mental health benefits of leisure beyond physical activity including critical examination of the potential negative health consequences of leisure. This includes three overlapping future directions for leisure studies: (i) more incisive attention to how health is being conceptualised, (ii) sharper exploration of the relevance and application of established and alternative meanings and models of health, and (iii) critical appraisal of the influence of diverse methodological strategies for the status and generation of knowledge about leisure and health. There are some areas of study which have received judicious attention by excellent scholars, but which have not yet been taken up extensively enough through the academy, such as within digital health and health entertainment, mental health and issues of health and the environment including health in human and non-human interactions. More work needs to be done to develop multidisciplinary and cross-sector partnerships through meaningful dialogues about knowledge production and knowledge exchange in leisure and health. This is needed so that the potential social, economic and political impact of leisure can be more fully realised. As public health scholars have come to recognise, in view of the social determinants of health, an area that arguably leisure studies researchers have explored for some time, there is a case for intersectionality frameworks of analysis to be bought to the fore in understanding complex, multiple and overlapping inequalities and their connection to leisure and health structures, processes and experiences. Framed in this way, leisure studies scholars can make a significant contribution to building and advancing knowledge about leisure and health. In doing so, such leisure scholarship can articulate evidence and progress understanding of the complex and overlapping possibilities and problems of leisure and human health to policy, professional practice and public/citizen audiences. 


\section{References}

Anderson, R. M. (1995). Patient empowerment and the traditional medical model: A case of irreconcilable differences?. Diabetes Care, 18(3), 412-415.

Antonovsky, A. (1996). The salutogenic model as a theory to guide health promotion. Health Promotion International, 11(1), 11-18.

Arai, S. \& Kivel, B. D. (2009). Critical race theory and social justice perspectives on whiteness, difference (s) and (anti) racism: A fourth wave of race research in leisure studies. Journal of Leisure Research, 41(4), 459-472.

Armstrong, D. (1993). Public health spaces and the fabrication of identity. Sociology, 27(3), 393-410. Bailey, P. (2014). Leisure and class in Victorian England: Rational recreation and the contest for control, 1830-1885. London. Routledge.

Bartky, S. L. (1988). Foucault, femininity, and the modernization of patriarchal power. In Feminism and Foucault: Reflections on Resistance, edited by I. Diamond and L. Quinby. Boston: Northeastern University Press.

Bartky, S. (1990). Femininity and Domination: Studies in the Phenomenology of Oppression. New York: Routledge.

Berdychevsky, L. \& Gibson, H. (2015). Women's sexual sensation seeking and risk taking in leisure travel. Journal of Leisure Research, 47(5), 621-646.

Bordo, S. (1993). Unbearable Weight: Feminism, Western Culture and the Body. London. University of California Press.

Bronfenbrenner, U. (1979). The Ecology of Human Development. Harvard University Press.

Dworkin, S. L., \& Wachs, F. L. (2009). Body panic: Gender, health, and the selling of fitness. nyu Press.

Engel, G. L. (1977). The need for a new medical model: A challenge for biomedicine. Science, 196(4286), 129-136.

Fullagar, S., Rich, E. \& Francombe-Webb, J. (2017a). New kinds of (ab) normal?: Public pedagogies, affect, and youth mental health in the digital age. Social Sciences, 6(3), 99.

Fullagar, S., Rich, E., Francombe-Webb, J. \& Maturo, A. (2017b). Digital ecologies of youth mental health: Apps, therapeutic publics and pedagogy as affective arrangements. Social Sciences, 6(4), 135. Caudwell, J. \& Browne, K. (2011). Sexy spaces: Geography and leisure intersectionalities. Leisure Studies. 30, 2. 117-122.

Clarke, J. \& Critcher, C. (1985). The Devil Makes Work: Leisure in Capitalist Britain. Macmillan International Higher Education.

Clift, S. \& Camic, P. M. (Eds.). (2016). Oxford Textbook of Creative Arts, Health, and Wellbeing: International Perspectives on Practice, Policy and Research. Oxford University Press, USA.

Curran, K., Rosenbaum, S., Parnell, D., Stubbs, B., Pringle, A., \& Hargreaves, J. (2017). Tackling mental health: the role of professional football clubs. Sport in Society, 20(2), 281-291.

Daykin, N. (2019). Arts, Health and Well-Being: A Critical Perspective on Research, Policy and Practice. London. Routledge.

Fox, K. (2006). Leisure and indigenous peoples. Leisure Studies, 25(4), 403-409.

Goodley, D. A. \& Moore, M. (2002). Disability Arts Against Exclusion: People with Learning Difficulties and Their Performing Arts. BILD publications.

Hargreaves, J. (1986). Sport, Power and Culture. A Social and Historical Analysis of Popular Sports in Britain. Cambridge. Polity Press. 
Hargreaves, J. (1994). Sporting Females: Critical Issues in the History and Sociology of Women's Sport. London. Routledge.

Hylton, K. (2005). 'Race', sport and leisure: Lessons from critical race theory. Leisure Studies, 24(1), 81-98.

Iwasaki, Y., Bartlett, J. G., Gottlieb, B. \& Hall, D. (2009). Leisure-like pursuits as an expression of Aboriginal cultural strengths and living actions. Leisure Sciences, 31(2), 158-173.

Floyd, M. F. (1998). Getting beyond marginality and ethnicity: The challenge for race and ethnic studies in leisure research. Journal of leisure research, 30(1), 3-22.

Jackson, L. A. (2008). 'The Coffee Club Menace' policing youth, leisure and sexuality in post-war Manchester. Cultural and Social History, 5(3), 289-308.

Kay, T. (2017). Bodies of knowledge: Connecting the evidence bases on physical activity and health inequalities. International Journal of Sport Polocy and Politics 8, 539-557

Lee, Y. \& Park, K. (2008). Does physical activity moderate the association between depressive symptoms and disability in older adults?. International Journal of Geriatric Psychiatry: A journal of the Psychiatry of Late Life and Allied Sciences, 23(3), 249-256.

Lehman, B. J., David, D. M. \& Gruber, J. A. (2017). Rethinking the biopsychosocial model of health: Understanding health as a dynamic system. Social and Personality Psychology Compass, 11(8) Liechty, T., Yarnal, C. \& Kerstetter, D. (2012). 'I want to do everything!': Leisure innovation among retirement-age women. Leisure studies, 31(4), 389-408.

Levins, R. \& Lopez, C. (1999). Toward an ecosocial view of health. International Journal of Health Services, 29(2), 261-293.

Maguire, J. \& Mansfield, L. (1998). 'Nobody's Perfect': Women aerobics and the body beautiful. Sociology of Sport Journal, 15, 109-137.

Malcolm, D. (2019). The Concussion Crisis in Sport. London. Routledge.

Mansfield, L. (2010). Fit, Fat and Feminine: The Stigmatisation of Fat Women in Fitness Gyms. In Women and Exercise: Qualitative Research on the Body, Health and Consumerism, edited by E. Kennedy and P. Markula, pp. 81-101. London: Routledge.

Mansfield, L. (2016). Resourcefulness, reciprocity and reflexivity: the three Rs of partnership in sport for public health research. International journal of sport policy and politics, 8(4), 713-729.

Mansfield, L. (2017). The imperative of physical activity in public health policy and practice. In Routledge Handbook of Physical Activity Policy and Practice (pp. 79-91). Routledge.

Mansfield, L., Kay, T., Anokye, N., \& Fox-Rushby, J. (2019). Community sport and the politics of ageing: co-design and partnership approaches to understanding the embodied experiences of lowincome older people. Frontiers in Sociology.

https://www.frontiersin.org/article/10.3389/fsoc.2019.00005

Mansfield, L., Daykin, N., \& Kay, T. (2020). Leisure and wellbeing. 39, 1. 1-10.

Mansfield, L. \& Rich, E. (2013). Public health pedagogy, border crossings and physical activity at every size. Critical Public Health, 23(3), 356-370.

Mansfield, L., \& Malcolm, D. (2014). 13 The Olympic Movement, sport and health. Health and elite sport: is high performance sport a healthy pursuit?, 187.

Maxwell, H., O'Shea, M., Stronach, M. \& Pearce, S. (2019). Empowerment through digital health trackers: An exploration of Indigenous Australian women and physical activity in leisure settings.

Annals of Leisure Research, 1-18.

Marmot, M. (2005). Social determinants of health inequalities. The Lancet, 365(9464), 1099-1104. Marmot, M. (2020). Health equity in England: The Marmot review 10 years on. BMJ, 368. 
Markula, P. (1995). Firm but shapely, fit but sexy, strong but thin: The postmodern aerobicizing female bodies. Sociology of Sport Journal, 12(4), 424-453.

Marshall, B. L. \& Katz, S. (2002). Forever functional: Sexual fitness and the ageing male body. Body \& Society, 8(4), 43-70.

Meadows, A. \& Bombak, A. E. (2019). Yes, We can ( No, you can't): Weight stigma, exercise selfefficacy and active fat identity development. Fat Studies, 8(2), 135-153.

Millington, B. (2017). Fitness, technology and society: Amusing ourselves to life. London. Routledge. Monaghan, L. F. (2014). Civilising recalcitrant boys' bodies: Pursuing social fitness through the antiobesity offensive. Sport, education and society, 19(6), 691-711.

McLennan, V. \& Khavarpour, F. (2004). Culturally appropriate health promotion: Its meaning and application in Aboriginal communities. Health Promotion Journal of Australia, 15(3), 237-239. Macdonald, D., Abbott, R. \& Jenkins, D. (2012). Physical activity of remote Indigenous Australian women: A postcolonial analysis of lifestyle. Leisure Sciences, 34(1), 39-54.

Napier, A. D., Ancarno, C., Butler, B., Calabrese, J., Chater, A., Chatterjee, H., ... \& Macdonald, A. (2014). Culture and health. The Lancet, 384(9954), 1607-1639.

Pedisic, Z., Shrestha, N., Kovalchik, S., Stamatakis, E., Liangruenrom, N., Grgic, J., ... \& Oja, P. (2019). Is running associated with a lower risk of all-cause, cardiovascular and cancer mortality, and is the more the better? A systematic review and meta-analysis. British Journal of Sports Medicine.

Pinto, R. Z., Ferreira, P. H., Kongsted, A., Ferreira, M. L., Maher, C. G. \& Kent, P. (2014). Self-reported moderate-to-vigorous leisure time physical activity predicts less pain and disability over 12 months in chronic and persistent low back pain. European Journal of Pain, 18(8), 1190-1198.

Pringle, R. (2003). Doing the damage? An examination of masculinities and men's rugby experiences of pain, fear and pleasure (Doctoral dissertation, The University of Waikato).

Pringle, R., Kay, T. \& Jenkins, J. M. (2011). Masculinities, gender relations and leisure studies: Are we there yet?. Annals of Leisure Research, 14(2-3), 107-119.

Ratna, A. (2017). Walking for leisure: The translocal lives of first generation Gujarati Indian men and women. Leisure studies, 36(5), 618-632.

Rich, E. \& Mansfield, L. (2019). Fat and Physical activity: Understanding and challenging weight stigma-special issue of fat studies: An interdisciplinary journal of body weight and society. Fat Studies, 8(2), 99-109.

Risner, D. \& Watson, B. (2021). (Eds.) Masculinity, Intersectionality and Identity: Why Boys (Don't) Dance. London: Palgrave Macmillan.

Russell, D. (1997). Popular Music in England 1840-1914: A Social History. Manchester University Press.

Rich, E. (2018). Gender, health and physical activity in the digital age: Between postfeminism and pedagogical possibilities. Sport, Education and Society, 23(8), 736-747.

Sassatelli, R. (2010). Fitness Culture: Gyms and the Commercialisation of Discipline and Fun. London Palgrave MacMillan.

Roderick, M., Smith, A., \& Potrac, P. (2017). The sociology of sports work, emotions and mental health: Scoping the field and future directions. Sociology of Sport Journal, 34(2), 99-107.

Samuels, K. (2015). The meanings in making: Openness, technology and inclusive music practices for people with disabilities. Leonardo Music Journal, 25, 25-29.

Shilling, C. (1993). The Body and Social Theory. London. Sage Publications.

Smith, B. \& Bundon, A. (2018). Disability models: Explaining and understanding disability sport in 
different ways. In The Palgrave Handbook of Paralympic Studies, edited by I. Brittain and A. Beacom, pp. 15-34. London: Palgrave Macmillan.

Smith, B. \& Perrier, M. J. (2014). Disability, sport and impaired bodies: A critical approach. In The Psychology of Sub-Culture in Sport and Physical Activity: A Critical Approach, edited by R.

Schinke \& K. R. McGannon, pp.95-106. London: Psychology Press.

Smith-Maguire, J. (2007). Fit for Consumption: Sociology and the Business of Fitness. London: Routledge.

Stickley, T.,\& Clift, S. (Eds.) (2017). Arts, Health and Wellbeing: A Theoretical Inquiry for Practice. Cambridge Scholars Publishing.

Thomas, C. (2007). Sociologies of Disability and IIIness: Contested Ideas in Disability Studies and Medical Sociology. Basingstoke: Palgrave Macmillan.

Tomlinson, A. (2005). Sport and Leisure Cultures (Vol. 6). University of Minnesota Press.

Tumasz, M. T., Trócoli, T., de Oliveira, M. F., Campos, R. R. \& Botelho, R. V. (2016). Do physically active patients have better functional outcome after stroke? A systematic review. Journal of Stroke and Cerebrovascular Diseases, 25(3), 527-532.

Van der Ploeg, H. P., Van der Beek, A. J., Van der Woude, L. H. \& van Mechelen, W. (2004). Physical activity for people with a disability. Sports Medicine, 34(10), 639-649.

Watson, B. \& Scraton, S. (2013). Intersectionality and leisure studies. Leisure Studies, 32(1), 35-47.

Watson, B. \& Rodley, I. (2015). Dazzling yet invisible: Boys in Cheerdance. In Invisible Boy: The Making of Contemporary Masculinities, edited by C. Hallgren et al., pp. 95-106. Sweden: Umea University Press.

Wittels, P. \& Mansfield, L. (2019). Weight stigma, fat pedagogy and rediscovering the pleasures of movement: Experiencing physical activity and fatness in a public health weight management programme. Qualitative Research in Sport, Exercise and Health, 1-18.

Wearing, B. (1995). Leisure and resistance in an ageing society. Leisure studies, 14(4), 263-279.

Wheaton, B. (2017). Surfing through the life-course: Silver surfers' negotiation of ageing. Annals of Leisure Research, 20(1), 96-116.

Williams, T. L., Smith, B. \& Papathomas, A. (2014) The barriers, benefits and facilitators of leisure time physical activity among people with spinal cord injury: A meta-synthesis of qualitative findings. Health Psychology Review, 8, 404-425.

Williams, T. \& Smith, B. (2017). Disability and physical activity. Routledge Handbook of Physical Activity Policy and Practice, 284-297.

Williams, T. L., Smith, B. \& Papathomas, A. (2018). Physical activity promotion for people with spinal cord injury: Physiotherapists' beliefs and actions. Disability and Rehabilitation, 40(1), 52-61.

Young, J., McGrath, R. \& Adams, C. (2018). Fresh air, sunshine and happiness: Millennials building health (salutogenesis) in leisure and nature. Annals of Leisure Research, 21(3), 324-346.

Zijlstra, H. P. \& Vlaskamp, C. (2005). Leisure provision for persons with profound intellectual and multiple disabilities: Quality time or killing time?. Journal of Intellectual Disability Research, 49(6), 434-448. 